\title{
Como morrem as democracias
}

\author{
POR Izabela Cavalcanti Pereira* \\ * Instituto Superior de Ciências Sociais e Políticas da Universidade de Lisboa, Portugal
}

Levitsky, S. \& Ziblatt, D. (2018). Como morrem as democracias. Lisboa: Vogais.

É urgente e contemporâneo o tema central deste livro. Desde a eleição de Donald Trump em 2016, como presidente dos Estados Unidos, acendeu-se um alerta preocupante sobre o futuro do regime democrático. Os cientistas políticos, Steven Levitsky e Daniel Ziblatt, investigam a cerca de 20 anos sobre colapsos das democracias pós-guerra-fria na América Latina e Europa, e conseguiram identificar comportamentos semelhantes de como líderes autocratas eleitos podem subverter gradualmente as normas democráticas. Nesta obra buscaram compreender os fenômenos que permitiram que o outsider Donald Trump chegasse à presidência dos Estados Unidos e a tentar entender o atual fenômeno político em que democracias consolidadas estão tornando-se enfraquecidas.

Steven Levitsky ${ }^{[1]}$ é professor de governo na Universidade de Harvard. Seus interesses em pesquisas incluem partidos políticos, autoritarismo e democracia, bem como fracas e informais instituições com foco na América Latina. Por sua vez, Daniel Ziblatt ${ }^{[2]}$ é professor da Eaton de Ciência do Governo na Universidade de Harvard e investiga a democratização, o colapso democrático, os partidos políticos, a construção do Estado e a economia política histórica, com ênfase na Europa do século XIX até o presente.

Nesta obra, os autores destacam a principal característica do fenômeno político contemporâneo: "o retrocesso democrático começa nas urnas". Longe de atos de ruturas a exemplo de "fechamento de congresso, golpe militar ou leis marciais" que transgridam de uma hora para a outra as normas democráticas, Levitsky e Ziblatt afirmam que as democracias estão a morrer porém de forma imperceptível para mui-

1. <https://scholar.harvard.edu/levitsky/home>.

2. <https://scholar.harvard.edu/dziblatt/home>. 
tos. As medidas governamentais estão sob véu da legalidade, inclusive sob o discurso de melhorar a democracia, "leis são aprovadas pelo Legislativo e aceitas pelo Judiciário. Além disso, os jornais continuam a circular e as eleições ocorrem regularmente". Segundo os cientistas políticos as instituições democráticas que não conseguem fazer barreira de proteção e são constrangidas pelos autocratas, estão sendo usadas como armas para controle sobre os que não estão no poder ou sobre os que podem ameaçar o governo.

A obra está dividida em nove capítulos, nos quais os autores elencaram as falhas das barreiras de proteção, as regras tácitas, as subversões, o desmantelamento e esboçaram possível salvação (será?).

O primeiro capítulo intitulado Alianças Fatídicas, Levitsky e Ziblatt enfatizam à importância da responsabilidade dos líderes partidários de filtrar os autoritários e/ou outsiders populistas na corrida eleitoral. Os autores reforçam que ao "abdicar dessa função, os líderes partidários, muitas vezes, marca o primeiro passo para o autoritarismo conseguir chegar ao poder", e citam como exemplos históricos Hitler, Mussolini e Chávez. Neste capítulo, retomam a obra de Juan Linz e Alfred Stepan, The Breakdown of Democratic Regimes (1978). A partir de Linz e Stepan, os autores desenvolveram uma 'prova dos nove' de um conjunto de sinais de alerta para ajudar na identificação de um autoritário: (1) "Rejeita, por palavras ou atos, as regras democráticas do jogo"; (2) "Nega a legitimidade dos adversários”; (3) “Tolera ou encoraja a violência"; ou (4) "Indica a sua disposição para restringir as liberdades cívicas dos adversários, incluindo os media”. Destacam que os políticos com mais tendências a conseguir afirmativamente corresponder a "prova dos nove" são os outsiders populistas ("políticos anti-aparelho").

Os professores de Harvard, citando Linz, entendem que as democracias falham muitas vezes por "maior afinidade [de um partido] com os extremistas do seu lado do espetro político do que com os partidos [mainstream] do lado oposto".

O segundo capítulo, A proteção da América, retomam as ideias dos fundadores do presidencialismo, da necessidade de um dispositivo interno de detação nas eleições "daqueles homens que derrubam as liberdades das repúblicas (...), começando como demagogos e terminando como tiranos", conforme escreveu Alexander Hamilton em o Federalista (1788). O dispositivo escolhido foi o Colégio Eleitoral. No entanto com o passar do tempo o colégio foi composto por membros leais aos partidos em vez de "notáveis locais" independentes, cedendo desta forma a sua autoridade de proteção da democracia aos partidos. Os partidos passaram a ser, de facto, os "administradores da democracia americana".

Levitsky e Ziblatt, no terceiro capítulo A Grande Abdicação Republicana, identificaram que "o sistema de primárias pós-1972 estava particularmente vulnerável a um tipo específico de outsider: indivíduos com fama ou capital suficientes para evitar as (primárias invisíveis)". Somando a isso, uma decisão do Supremo Tribunal, de 2010, possibilitou que mesmo "candidatos marginais" pudessem ter acesso a grandes quantias de fundos. Também houve um "aumento (explosão) dos media alternativos, 
em particular os canais de notícias por cabos e as redes sociais. O que os autores chamaram de "complexo de entretenimento conservador".

Para os professores de Harvard, "os guardiões do Partido Republicano fracassaram em três encruzilhadas: nas primárias invisíveis, nas primárias e nas eleições gerais". Afirmam que com exceção de Richard Nixon (presidente dos EUA de 1969 a 1974), nenhum candidato presidencial dos principais partidos preencheu um só desses critérios da 'prova dos nove'. Todavia, em 2016, mesmo com o candidato apresentando características autoritárias (cumpria os quatro critérios da 'prova dos nove') a "maior parte dos líderes Republicanos cerrou fileiras atrás de Trump, criando a ideia de um partido unificado".

O quarto capítulo, A Subversão da Democracia, traz a pergunta: "Como é que os autoritários eleitos destroem as instituições democráticas que se supõe constrangê-lo?". Os autores exemplificam o caso do Peru, na América Latina, com Fujimori (outsider), que em menos de dois anos de sua "eleição-surpresa" fechou o Congresso e convocou uma nova Constituinte. Embora, os cientistas políticos reforçarem que o "colapso democrático não precisa de modelo", ressaltam que os atos do Executivo se revestem de legalidade, principalmente, em época de crises econômicas, ambientais ou de segurança, endoçados com o apoio dos cidadãos "sobretudo quando receiam pela sua própria segurança”.

Levitky e Ziblatt pontuam que a maior perceção sobre a falência atuais das democracias está nos passos lentos e sorrateiros: "ao fazer os árbitros reféns, comprar ou enfraquecer os adversários, bem como reescrever as regras do jogo, os líderes eleitos podem estabelecer uma vantagem decisiva - e permanente - sobre os adversários".

Para os autores, as barreiras de proteção da Democracia (título do quinto capítulo) vão além de regras escritas (constituições, leis) e árbitros (tribunais congresso), mas pelo respeito dos participantes políticos às regras tácitas e à tolerância mútua. Sendo essa tolerância mútua a "disposição coletiva dos políticos para concordar com a discórdia”. O respeito às regras tácitas e o autolimite são necessários para que a competição não resulte num campo de batalha, causando a erosão das barreiras.

Um dos pontos mais importante trazidos à clareza por Levitsky e Ziblatt com este estudo sobre a democracia americana foi que as barreiras de proteção e a tolerância mútua foram estabelecidas "apenas depois de a questão da igualdade racial ter sido removida da agenda política”. No sexto capítulo, As Regras Tácitas da Política Americana, os autores retomam o início da República americana sem barreiras de proteção que os levaram à Guerra Civil (1861-1865), motivada por divergência sobre o futuro da escravatura (o sul colonial versus o norte abolicionista).

Paradoxalmente, as normas do civismo político (respeito às regras tácitas e o autolimite) que viria representar a política americana do século xx "nasceram de um acordo profundamente antidemocrático: a exclusão racial e a consolidação do governo de partido único no Sul”. Sem esse tema na agenda política, os principais partidos tinham muitas ideias em comum, bem como estavam em sua composição restritos em sua grande maioria aos brancos. Apenas na década de 1960, que o pro- 
cesso de inclusão racial ganhou força, resultando na Lei dos Direitos Civis de 1964 e na Lei de Direitos Eleitorais de 1965. Para os autores, finalmente o país foi democratizado, mas voltou a "polarizá-lo."

A polarização extrema é o tema central do sétimo capítulo, intitulado Desmantelamento. Levitsky e Ziblatt mostram com o exemplo da recusa do Senado para considerar uma indicação ao Supremo Tribunal feita por Obama em meados de 2016, o nível de intolerância e não cooperação em que tinham chegado a política dos Estados Unidos. "Pela primeira vez na história dos EUA o Senado recusou sequer considerar a nomeação". A intolerância passou a ser "politicamente útil”. Em seus dois mandatos Obama enfrentou o "crescimento do extremismo e da guerrilha sectária", sendo esta iniciada na década de 1970, com os Republicanos adotando uma política de "guerra ao poder".

Para explicar o aprofundamento da polarização, os autores ressaltam a mudança no mapa demográfico americano, tornando a diversificação étnica um fenômeno crescente nos EUA e que não se "limitou à emancipação dos negros na década de 1960", mas também, na mesma década, iniciou-se "onda gigante" da imigração primeiramente dos latinos e, em seguida, dos asiáticos. "O Instituto Americano de Estatística estima que a maioria da população será não-branca em 2044”. Os Republicanos se mantiveram homogêneos com os "verdadeiros americanos" enquanto os Democratas passaram a obter preferência cada vez mais da população diversificada e de contínuo crescimento. A polarização dos dois principais partidos está profundamente estabelecida, uma vez que os seus eleitores atualmente estão "divididos por raça, religião, geografia e até o modo de vida". Os cientistas políticos destacam que as questões de raça e religião "têm tendência de gerarem mais hostilidade e intolerância do que questões políticas tradicionais como os impostos e a despesa governamental”. Escolher um partido nos EUA passou a "ser uma identidade", a escolha de um dos lados da trincheira.

Nenhum país é imune as transformações sociais muito menos as reações dos grupos sociais dominantes, reações essas provocadas pelas ameaças as relações de poder historicamente estabelecidas. O conservadorismo levado ao extremo nos tempos atuais é um grande termômetro no sentido de que as mudanças são profundas e estão, de facto, quebrando as barreiras que antes eram difíceis de transpor, tornando-se reais ameaças às estruturas de poder. E na guerra pelo poder ou a manutenção do status quo perderam-se os escrúpulos, bem como a ideia principal da democracia. Pontualmente, dois movimentos de oposição surgiram no Governo de Obama, o Tea Party ${ }^{[3]}$ e o Birther. ${ }^{[4]}$ "O mais infame de todos os birthers foi Donald Trump".

3. Tea Party: ala radical do partido Republicano, mas é um movimento que envolve comunicação, empresários e sociedade civil. O nome remete ao Tea Act em 1773, em que americanos incendiaram um navio de carga de chá da Inglaterra em protesto às taxas. Esse ato ganhou adesão e futuramente iria promover a Revolução Americana, resultando na Independência dos Estados Unidos.

4. Birther: algo como os verdadeiros americanos. Movimento que constantemente colocou em questão a cidadania do presidente Obama (insinuando que não tinha nascido nos EUA), bem como a sua aproximação com terroristas muçulmanos. 
No oitavo capítulo, Trump Contra as Barreiras de Proteção, os professores de Harvard demonstram como Trump apresentou "evidente instinto autoritário" ao agir no primeiro ano do mandato. Os cientistas elencam três ações características de autoritários para consolidar o poder: (1) fazer dos árbitros reféns; (2) afastar os jogadores principais; e (3) reescrever as regras do jogo para enviesar o tabuleiro contra os adversários. "Trump tentou todas as três".

Para Levitsky e Ziblatt, "mesmo que Donald Trump não desmantele diretamente as instituições democráticas, a sua violação das normas vai quase certamente corroê-las". Os autores concordam com a opinião de David Brooks (comentarista político do New York Times) que "(Trump) rebentou com os padrões de comportamento que governaram em tempos a vida pública. $\mathrm{O}$ seu partido recompensou-o nomeando-o para presidente". E isso não vem sem um preço a pagar, pois ao não se respeitar as regras do jogo e expandido o aceitável (tolerável) de um comportamento político "podem deixar a democracia em perigo".

No último capítulo, A Salvação da Democracia, os investigadores americanos reconhecem que a democracia desenvolvida pelos EUA "não é tão excecional (...) não há nada que nos vacine contra o colapso democrático". Até meados de 1960, a estabilidade política dos EUA estava fundamentada na exclusão racial e em governo autoritário de partido único no Sul. Após isso uma onda de polarização cresceu no país e "mais profunda do que em qualquer momento desde o fim da Reconstrução (pós-Guerra Civil)". Ressaltam que em "um país cujo presidente ataca a imprensa, ameaça prender a sua rival (Hillary Clinton) e declara que pode não aceitar resultados eleitorais já não pode defender credivelmente a democracia”.

Por fim, os professores de Harvard apontam três futuros possíveis para a América pós-Trump. O primeiro, “e o mais otimista, é uma rápida recuperação democrática. Neste cenário, Trump falha politicamente: perde o apoio do público e não é reeleito, ou, de modo mais dramático, é impugnado ou forçado a demitir-se". O segundo, "e muito mais negro futuro é aquele no qual Trump e os Republicanos continuam a ganhar com um apelo nacionalista branco. Neste cenário, um GOP pró-Trump manteria a presidência, ambas as câmaras do Congresso e a grande maioria das câmaras estaduais, e acabaria eventualmente por obter uma maioria sólida no Supremo Tribunal”. Por fim, o terceiro, “e em nossa opinião (dos autores) o mais provável, é um futuro marcado pela polarização, por mais afastamentos das convenções políticas tácitas e por uma crescente guerra institucional - por outras palavras, uma democracia sem barreiras de proteção sólidas".

Em tempos extremos e sombrios para a manutenção da democracia, Levitsky e Ziblatt defendem que as coligações mais eficazes serão aquelas que juntarão "grupos com opiniões díspares - mesmo opostas - sobre muitas questões. Serão construídas não entre amigos, mas entre adversários”. 